\title{
MicroRNA-141 Inhibits the Proliferation of Penile Cavernous Smooth Muscle Colls Associated with Down-Regulation of ti Rhoa/Rho Kinase Signaling Pathwa
}

\author{
Ying Zhang ${ }^{a}$ Linpei Jiab ${ }^{b}$ Wei Jic Hai Li ${ }^{d}$
}

aDepartment of Pathology, China-Japan Union Hospital of Jilin $U$ Nephrology, Xuanwu Hospital, Capital Medical University, Beijing, Provincial People's Hospital, Changchun, 'Department of Urology, University, Changchun, P.R. China

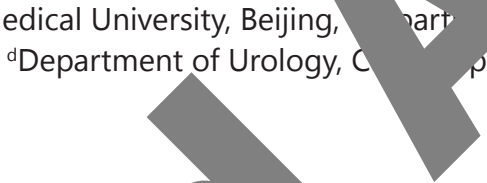

\section{Key Words}

Microrna-141 • Diabetes mellitus erectil Rho $\cdot$ Rho kinase II

\section{Abstract}

Background/Aims: The role induced erectile dysfuncti has RhoA/mo kinase signaling pathway in diabetes mellituswe explored the change diabetic erectile dysfun signaling pathway in vitr is the Rin Rho associated kinase (ROCK) signaling pathway in in ivo and the effects of microRNA-141 on the RhoA/ROCK The mRNA and protein expressions of RhoA and ROCK2 were significant' ed wrme the expression of microRNA-141 was decreased in the penile cavernous sm an alls of rats with diabetic erectile dysfunction. Moreover, increased expression mic N 41 , decreased expressions of RhoA and ROCK2 (mRNA and protein), acceler ell pi ation rate and reduced cell apoptosis were found in the microRNA-141 rimirs $y$ and the siRNA-Rho group. The microRNA-141 expression in the microRNA-141 ors - A-Rho group was significantly decreased. microRNA-141 specifically bound 3'-UTM and down-regulated the expression of Rho gene at the post transcriptional sion: Decreased expression of miR-141 is associated with up-regulation of RhoA

ROCK 2 in the RhOA/ROCK signaling pathway in rats with diabetic erectile dysfunction. 1 41 inhibits the growth of penile cavernous smooth muscle cells associated with downration of the RhoA/ROCK signaling pathway in vitro.

\section{Introduction}

Patients with diabetes mellitus (DM) are subject to chronic complications with increasing morbidity and mortality $[1,2]$. Erectile dysfunction (ED) refers to the inability to keep the penile erection for a kind of sexual behavior [3]. As one of the complications 


\section{Cellular Physiology Cell Physiol Biochem 2018;48:348-360 \begin{tabular}{c|c} 
DOI: 10.1159/000491741 & $\begin{array}{l}\text { O 2018 The Author(s). Published by S. Karger AG, Basel } \\
\text { www.karger.com/cpb }\end{array}$
\end{tabular} \\ Zhang et al.: MiRNA-141 and DMED}

of DM, ED generally occurs in elderly patients [4]. Additionally, orgasmic dysfunction is often associated with ED patients combined with type 2 diabetes mellitus (T2DM) [5]. Low testosterone levels may partially account for the pathogenesis of DMED; a recent study showed that men with T2DM had a low testosterone level that may lead to low sex drive and ED [6]. Furthermore, other factors including old age and low penile blood flow may al contribute to the occurrence of DM-induced ED (DMED) [7].

Rho associated kinase (ROCK) is a serine/threonine kinase that interacts with activated Rho GTPases and the RhoA/ROCK signaling pathways control an extensive essential functions, including cell adhesion, motility, proliferation, differentiation, and apop [8]. ROCK2 was significantly up-regulated in the cavernous smooth musc or myofibroblasts of patients with ED, and ROCK1 inhibitor Y-27632 caused a relaxation of corpus cavernosum in tissue strips of patients with severe EF 97

microRNA (miR) is a kind of short non-coding RNA, which acts as conserved regulator of gene expression [10]. miR is a single stranded $\Upsilon$. a length of about 18-23 nucleotides and exerts its functions in regulat geno ession by pairing base-pairing with the 3' untranslated region of the targe NA [11]. The role of miR in DMED has been scarcely studied. Li et al. show to miR-s tagomir could improve ED in streptozotocin (STZ)-induced diabetic ra reviou cudy indicated that the inhibition of miR-141 was associated with cell cy ap growth, migration and invasion in cancer cells; bromodomain-containing prote protein (UBAP)1 and phosphatase and tensir molog (PT miR-141 [13]. Over-expression of miR-141 dec. d mitocho lal superoxide dismutase and catalase activities, and increased reactive oy- ecies (RUS) levels in cardiomyocytes exposed to glucose fluctuations [14].

Over-expression of miR-200a was recogr with aging-related ED and the chief tar nat. in $\rightarrow$ orpus cavernosum tissues of rats as endothelial nitric oxide synthase (eNOS)/nitric oxide (NO)/protein kir to $K$ G), which is an important pathway involved in the physiology of normal erection far, the role of the RhoA/ROCK signaling pathway in DMED has been lly od and the mechanism of miR in DMED is unclear. Thus, we aim to pro the encet of miR-141 on DMED by targeting the RhoA/ ROCK pathway in rats with M.

Materials and Meth

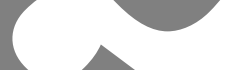
of Jilin $U$ ity. Th dy was conducted in strict accordance with the guidelines for both the care a d yee o, atory animals. All efforts were made to minimize the number of animals used and their ins. $>$

pecric pathogen free (SPF) male Sprague-Dawlay (SD) rats were purchased from the Slac Laboratory Company (Shanghai, China) and were housed on a 12/12 light-dark schedule with water and vailable ad libitum. Detailed accommodation and care complied with Chinese recommendations nd legislations. Ninety-five rats at 10 -week old with mean body weight $287.8 \mathrm{~g}$ were selected for our experiments. The mating test showed that the sexual function of all rats was normal. Twenty rats were randomly selected as the normal group and another 75 into the observation group.

\section{Construction of the DMED model}

After fasted for 8-12 h, rats were intraperitoneally injected with STZ (40 mg/kg) (Sigma, USA) to induce the DM model. Symptoms were recorded of after STZ injection, and tail-cutting method and Roche blood glucose meter (Roche Company, Germany) were daily performed to detect the blood glucose level from the fourth day. The model was successfully established when the random serum glucose level reached 


\section{Cellular Physiology Cell Physiol Biochem 2018;48:348-360 \begin{tabular}{c|c} 
DOI: 10.1159/000491741 & $\begin{array}{l}\text { O 2018 The Author(s). Published by S. Karger AG, Basel } \\
\text { www.karger.com/cpb }\end{array}$
\end{tabular}}

Zhang et al.: MiRNA-141 and DMED

more than $16.67 \mathrm{mmol} / \mathrm{L}$. The blood glucose level was measured once a week and when the value reached over $25 \mathrm{mmol} / \mathrm{L}$, 2IU protamine zinc insulin was injected subcutaneously to rats. DM rats were placed into the metal cages and fed for 10 weeks. A total of $100 \mathrm{~g} / \mathrm{kg}$ apomorphine hydrochloride (APO) (Shenyang First Pharmaceutical Factory, Shenyang, China) was injected into the soft skin of neck by subcutaneous injection. Rats were observed by a video recorder from the bottom of the cage for $30 \mathrm{~min}$ and the erection times we recorded. The standards of penile erection in rats: the prepuce was receded, and the penis was enlarged an the glans was exposed. Rats without penile erection were used as DMED rats. The penile cavernous bodies were removed when all animals were sacrificed at the end of 12 weeks after modeling. A total of $10 \mathrm{pe}$ cavernous bodies were fixed with $4 \%$ paraformaldehyde, and embedded with paraffin, and-cut into sections. The remaining samples were snap-frozen with liquid nitrogen and then stored at

\section{Hematoxylin-eosin (HE) staining and Masson staining}

Neurovascular tissues in suspensory ligament of phalange and proximal and dis dorsalis of penis were extracted. Samples were fixed with $4 \%$ paraformaldehyd cavernosum tissues were removed from the fixative solution. Routine dehydratiol gradient alcohol of 70\%, 80\%, 90\%, 95\%, and 100\%, xylene transparenting (tw and paraffin embedding were done and $5 \mu \mathrm{m}$ paraffin sections were The dim of slices were performed, after which were spread and fished at at at The HE staining was performed, followed by gradient alcohol dehydration and xylc ran and then all slides were mounted with neutral balata. The Masson staining was used $t$ suls. cells from surrounding connective tissue. Pathological changes of spongy tissy f corpus cave
microscope (Olympus, Japan).

\section{Immunohistochemistry}

The samples were firstly fixed with paraformal de an wedded with paraffin with a thickness of $4 \mu \mathrm{m}$. Tissues were incubated at $60^{\circ} \mathrm{C}$ for 1 ures of the conventional xylene dewaxing together with the gradient alcohol dehydrat with distilled water for 3 times and each tir antigen, bathed with cold water ole temperature, and phosphate buffer saline (PBS) washing was done for 3 times ( $3 \mathrm{n}$ h time).-.uvine serum albumin (BSA) blocking solution was added into samples and the samples y $\quad 37^{\circ} \mathrm{C}$ for $30 \mathrm{~min}$. Slices were removed and dried, and added into rabbit monoclonal anti es Rho S00, Abcam, Cambridge, UK) at $4^{\circ} \mathrm{C}$ overnight. Slices were rinsed with PBS for 3 times in ear time). The secondary antibody of sheep anti-rabbit RhoA (1:2000, Abcam, Cambridge, UK) was samples and incubated at $37^{\circ} \mathrm{C}$ for $30 \mathrm{~min}$. Samples were washed with PBS for 3 tim eacirnie). Streptomycin avidin-peroxidase solution (ZSGB Biotechnology Co., Ltd., Beijing, Chi of ito samples and were incubated at $37^{\circ} \mathrm{C}$ for $30 \mathrm{~min}$. Diaminobenzidine (DAB) staining sol n (B Bi mology Co., Ltd., Beijing, China) was added. The reaction was terminated by using wa slict displayed on shelf after their color displayed, and socked into purified water f 5 min. les were washed with hematoxylin for $5 \mathrm{~min}$ and then washed with tap water. Slices were $d$ an. $\quad d$ with $1 \%$ hydrochloric alcohol and stained in blue with tap water for 20 min. Staining vere di ued into two kinds: positive and negative. Positive staining was found in the cytoplasm and in cells showing brown yellow granular, and negative staining was found in the cytoplasm and eus orcells without showing brown yellow granular. Positive expression rate = positive cells number/ sta" plls number X $100 \%$.

Quantitative real-time polymerase chain reaction ( $q R T-P C R$ )

Total RNAs from corpus cavernosum tissues of rats in each group were extracted by Kit (Invitrogen Company, Shanghai, China). After identifying the purity and integrity of RNA, miR-141, RhoA, ROCK1, ROCK2 primers were designed and synthesized by TaKaRa company (Dalian, China). The RNA template, Primer Mix, dNTP Mix, DTT, RT Buffer, HiFi-MMLV, and enzyme without RNA were placed on the ice and dissolved for further use. The system of $20 \mu \mathrm{L}$ was reversely transcripted according to TaqMan MicroRNA Assays Reverse TranscriptioN Primer (Thermo Fisher Scientific), the reaction conditions were as follows: $42^{\circ} \mathrm{C}$ for 30-50 min (reverse transcription reaction) and $85^{\circ} \mathrm{C}$ for $5 \mathrm{~s}$ (enzyme inactivation reaction of reverse transcriptase). The reaction solution was taken for qRT-PCR by referring to KIT SYBR Premix Ex TaqTM

\section{KARGER}


Zhang et al.: MiRNA-141 and DMED

II kit (RR820A, Action-Award Biological Technology Co. Ltd.) instructions for quantitative PCR operation. The reaction condition was: 40 cycles of predenaturation at $95^{\circ} \mathrm{C}$ for $10 \mathrm{~min}$, denaturation at $95^{\circ} \mathrm{C}$ for $10 \mathrm{~s}$, annealing at $60^{\circ} \mathrm{C}$ for $20 \mathrm{~s}$, and extending at $72^{\circ} \mathrm{C}$ for $34 \mathrm{~s}$. The reaction system was: $10 \mu \mathrm{L}$ SYBR Premix Ex TaqTM II, $0.8 \mu \mathrm{L}$ PCR Forward Primer $(10 \mu \mathrm{M}), 0.8 \mu \mathrm{L}$ PCR Reverse Primer (10 $\mu \mathrm{M}), 0.4 \mu \mathrm{L}$ ROX Reference Dye and 2.0 $\mu \mathrm{L}$ cDNA template, and $6.0 \mu \mathrm{L}$ sterile purified water. The U6 was used as internal reference miR-141, and $\beta$-actin (Absin Bioscience Inc., Shanghai, China) acted as internal reference of RhoA, ROCK and ROCK 2. $2^{-\Delta \Delta C t}$ was the ratio of gene expression of experimental group and the control group, the formula was as follows: $\Delta \Delta \mathrm{CT}=\Delta \mathrm{Ct}_{\text {(experimental group) }}-\Delta \mathrm{Ct}_{\text {(control group) }}$ of which $\Delta \mathrm{Ct}=\mathrm{Ct}_{\text {miRNA }}-\mathrm{Ct}_{\mathrm{RhoA}}$. $\mathrm{Ct}$ was the numbe amplification cycles when the real time fluorescence intensity of the reaction reached a threshold valu the amplification corresponded to logarithmic growth (Table 1).

\section{Western blotting}

Liquid nitrogen was added into the penile cavernous smooth muscle cells, and it tissues showed fine powder uniformly. Then the protein lysate was placed on ice, grip and vortexed once every $10 \mathrm{~min}$. Supernatants were obtained to determine the prot bicinchoninic acid (BCA) method (20201ES76, Yi Sheng Biotechnology Co. Ltd, S. layer was abandoned and centrifuged at $2000 \mathrm{Xg}$ and $4^{\circ} \mathrm{C}$ for 20 Droteins neasured and the deionized water was adjusted to ensure that the sample loading wo about sodium dodecyl sulfate (SDS) separation gel and concentration gel were allocated. ple ixed with the loading buffer, boiled at $100^{\circ} \mathrm{C}$ for $5 \mathrm{~min}$, and added into each lane for ionop par. on with a micropipette after ice bath and centrifugation. Then the protein $y$ ransferred $p$ in gel to nitrocellulose filter (NC filter). $5 \%$ skimmed milk powder was sealed off $\mathrm{m} \quad$ filter at $4^{\circ} \mathrm{C}$ rnight. The primary antibody (rabbit monoclonal antibodies, namely anti-RhoA (1:10 i-ROCK (1:500), anti-ROCK 2 (1:250) and anti- $\beta$-actin (1:1000), all from Abcam, Cambridge, $V$ wer bated overnight at room temperature, washed with PBS for 3 times (5 min each time). Go ti-ra igG (1:1000, Boster Company, Wuhan, China) labeled with horseradish peroxidase $d$, and then the secondary antibody was incubated at $37^{\circ} \mathrm{C}$ for $1 \mathrm{~h}$. Samples were rins $\quad$ v $\quad S$ at room temperature for 3 times ( 5 min each time). The NC filter was immersed in electrocher temperature for $1 \mathrm{~min}$. The resu $>$ r development and fixation. $\beta$-actin served as the internal reference, and the relative sions o. protein were expressed as the ratio of gray value of target band and internal reference bo

\section{Cell culture}

The penis of DMFn rat tunica albuginea ? transferred into transferred into
(DMEM) an ashe th 3 for 3 times, tissue b
Cells wer

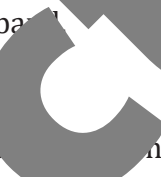
$>$ of puns were removed as much as possible. Corpora cavernosum penis were nntaining a small amount of Dulbecco's modification of essential medium $C$ itherbu. USA) containing 10\% fetal bovine (FBS) Gaitherburg, MD, USA) at $37^{\circ} \mathrm{C}$ CO. S, sle cell suspension was obtained issues with $0.25 \%$ trypsin (Gibco, herburg, MD, USA). Then cells were cultured
ad assaged conventionally. Finally, cells in the thmic growth phase were used for further speriments.

\section{Cell transfection}

Cells in the logarithmic growth phase of the cavernous tissues of rats were inoculated in a 6-well plate, and the cell density was increased to 30\%-50\%. The cells were transfected according to instructions of lipofectamin 2000 (Invitrogen Corp., USA). Opti-MEM serum-free medium (250

Table 1. Primers sequences of quantitative real-time polymerase chain reaction (qRT-PCR). Notes: ROCK: Rho-associated protein kinase; F, forward; R, reverse

\begin{tabular}{lc}
\hline Gene & Gene sequences \\
\hline miR-141 & R: 5'-CAUCUUCCAGUACAGUGUUGGA -3' \\
& F: 5'-UAACACUGUCUGGUAAAGAUGG -3' \\
U6 & R: 5'-CTCGCTTCGGCAGCACA-3' \\
& F: 5'-AACGTTCACGAATTTGCGT-3' \\
RhoA & R: 5'-TGACCGCCTGTAGCCTTGAC -3' \\
& F: 5'-CCCACTCGCCCTGATTTATG -3' \\
ROCK 1 & R: 5'-TGATGGCTATTATGGACGAG -3' \\
& F: 5'-GGAGCGTTTCCCAAGC -3' \\
ROCK 2 & R: 5'-CCTGTCAAGCGTGGTAGTGA -3' \\
& F: 5'-TTAGTGTTGTTCCGCACAGG -3' \\
3-actin & R: 5'-AGGGAAATCGTGCGTGAC-3' \\
& F: 5'-ACCCAGGAAGGAAGGCT-3' \\
\hline
\end{tabular}




\section{Cellular Physiology and Biochemistry \\ Cell Physiol Biochem 2018;48:348-360 \\ \begin{tabular}{l|l}
\hline DOI: $10.1159 / 000491741$ & (C) 2018 The Author(s). Published by S. Karger AG, Basel
\end{tabular} \\ Zhang et al.: MiRNA-141 and DMED}

$\mu \mathrm{L}$ ) (Gibco, NY, USA) was used to dilute 100 pmol plasmids in the NC group, miR-141 diluted inhibitors, miR-141 mimics, miR-141 inhibitors + siRNA-Rho groups (diluted the final concentration of each cell is 50 $\mathrm{nM}$ ), vortexed gently and incubated at room temperature for $5 \mathrm{~min} ; 250 \mu \mathrm{L}$ serum-free Opti-MEM medium was used to dilute $5 \mu \mathrm{L}$ lipofectamin 2000, vortexed gently and incubated at room temperature for $5 \mathrm{~min}$. The two samples were mixed, incubated at room temperature for $20 \mathrm{~min}$ and added into the cell culty wells. Mixed cells were cultured at $37^{\circ} \mathrm{C}$ with $5 \% \mathrm{CO}_{2}$ for $6-8 \mathrm{~h}$. After another $24-48 \mathrm{~h}$, cultured cells we used for subsequent experiments.

\section{Luciferase reporter gene assay}

Biological prediction website microRNA.org showed that miR-141 can target Rho. Lu gene assay was performed to verify whether Rho was a direct target of miR-141. The artificially Rho 3'UTR were introduced into the pMIR-reporter by restriction site of Spel and Hin $I$ (MUT) site of complementary sequence of seed sequence was designed on the basis (WT). After digestion with restriction endonuclease, the target segments were in reporter plasmid byT4 DNA ligase. The plasmids (WT and MUT), which were sad transfected into HEK-293T cells by co-transfection with miR-141. After $48 \mathrm{~h}$. collected and lysed, and the luciferase activity was detected by th iferase as it (Genomeditech, China).

\section{3-(4, 5-dimethylthiazol-2-yl)2, 5-diphenyl tetrazolium bromide (M}

The corpus cavernosum tissues at the logarithmi owth phase twice and digested with $0.25 \%$ trypsin when the cell v reached a suspension at $2.5 \times 10^{5} / \mathrm{mL}$ was prepared with RPMI16 96-well culture plates and cultured. The culture plat and $5 \mathrm{mg} / \mathrm{mL}$ MTT (Sigma-Aldrich, St. Louis, MO, USA the optical density (OD) value at $490 \mathrm{~mm}$ was ere ed at $24 \mathrm{~h}, 48 \mathrm{~h}$ and $72 \mathrm{~h}$, respectively, collected, washed with PBS for 80\% after transfection. Cell tomatic microplate reader.

Flow cytometry

Cells were collected after 48 of sample cells was adjusted to 1 was $70 \%$ ) was used to fix cello 4 c $\mathrm{ml} 50 \mathrm{mg} / \mathrm{L}$ propidium iodid for $30 \mathrm{~min}$, and then filtere Company, New Jersey USA) 1) dye liq 2 sted with $0.25 \%$ trypsin solution. The concentration $\mathrm{nL}$ cels $(-1 \mathrm{~nL})$. The pre-cooling alcohol solution (volume fraction Cells were washed with PBS for twice the next day, and 1 th nyl mesh filters. Flow cytometry (FACS Calibur, Becton and Dickinson med to record the cell cycles. Apoptosis was detected by Annexin V-FITC/PI double Cells were cultured in an incubator at $37^{\circ} \mathrm{C}$ with $5 \% \mathrm{CO}_{2}$ for $48 \mathrm{~h}$. Cells were collected and th $\mathrm{ir}$ PBS for twice. The cells were resuspended into $200 \mu \mathrm{L}$ binding buffer after centrifugati $10 \mu$, ne $\checkmark$-FITC and $5 \mu \mathrm{L}$ PI solution were added for detecting the cell apoptosis at the excitation $38 \mathrm{~nm}$ with flow cytometry.
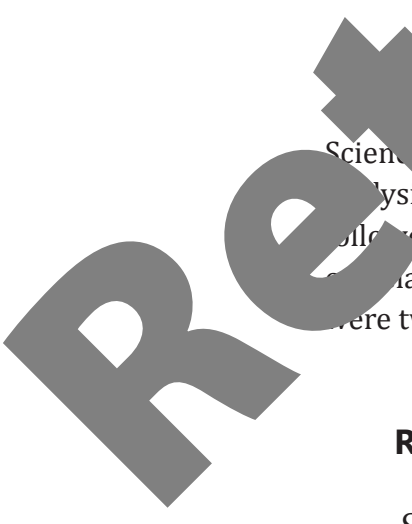

atistio

ta were resented as mean values \pm standard deviations (SD). The Statistical Program for Social ) 21.0 software (SPSS, IBM, West Grove, PA, USA) was used for data analysis. The one-way ysis or variance (ANOVA) and the Kruskal-Wallis test were used to compare values among groups red by the Student's t-test or the Mann-Whitney U-test to compare values between groups. The Pearson ation analysis was carried out for the analysis of the correlation of two variable quantities. All tests ere two-tailed, with the level of significance set to $P<0.05$.

\section{Results}

\section{Successful establishment of the DMED model}

We found that modeling rate of DM was low when rats were injected with STZ at the dosage of $35 \mathrm{mg} / \mathrm{kg}$ per time, and the mortality rate would increase when rats were injected with STZ at the dosage of $60 \mathrm{mg} / \mathrm{kg}$ per time. No rats died when they were injected with STZ 
Zhang et al.: MiRNA-141 and DMED

at the dosage of $40 \mathrm{mg} / \mathrm{kg}$, and all developed DM. Thus, the optimal dosage was set to 40 $\mathrm{mg} / \mathrm{kg}$. The weight and blood glucose level of rats were shown in Table 2. The body weight in the DMED group was obviously lower in comparison with the normal group (all $P<0.05$ ). After the normal and the DM rats were injected with apomorphine hydrochloride, the penile erection rates of diabetic rats were obviously reduced at the $10^{\text {th }}$ week as compared with $t^{t}$ normal controls (all $P<0.05$ ).

\section{Pathological changes of the corpus cavernosum tissues in DMED}

HE staining showed that in the normal group, penile corpora cavernosum-contair large number of sinusoids; the trabecula of sinusoid contained a large numb of coll fibers and smooth muscles (Fig. 1A). The DMED group presented increased col density in the penile corpora cavernosum, thickened penile vascular wa number of smooth muscles and irregular lumen. In the normal group, cal were distributed regularly, cavernous smooth muscle (Masson stainin arranged according rules. The penis of rats in the DMED group becam of sinusoids were reduced, and stromal component (Masson sta was green) were increased (Fig. 1B).

Expression of RhoA was up-regulated in the corpus cav

Immunohistochemistry was used to detect the expr cavernosum tissues of rats with DMED. The exp cion of Rho. tein was strongly positive in the penile corpus cavernosum tissues of rats DMED gr, and was weakly positive or negative in rats of the normal group (Fig. 1. npared with the normal group, the expression of RhoA protein in the penile cor ca sum tissues of rats in the DMED group was significantly up-regulated (Fig. 1D)

miR-141 was down-regulated and KTHOA and ROCK2 was up-regulated in DMEM

qRT-PCR was used to detect the ex of miR-141 and mRNA expressions of related proteins in the RhoA/ROCK in the penile corpus cavernosum tissues of rats. The expression of miR- the Diva $D$ group was remarkably lower than that in the normal group $(P<0.05)$. $C$ nat the normal group, the mRNA expressions of RhoA and ROCK2 were signifir ay highe the DMED group (both $P<0.05$ ), while there was no statistical significance it $\mathrm{mR}^{\mathrm{N}} \mathrm{A}$ expression of ROCK1 between the two groups $(P>0.05)$ (Fig. 2A).

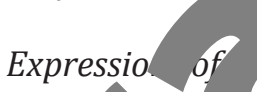

The $\mathrm{p}$ ein $r e$ wns of RhoA, ROCK1 and ROCK2 in the penile corpus cavernosum tissues ts wt tected by Western blotting. Compared with the normal group, the e'vress $\quad$ RhoA and ROCK 2 protein were significantly increased in the penile corpus 1osul yes of rats in the DMED group (both $P<0.05$ ), the expression of ROCK1

2. Iges of blood glucose level and body weight of rats before and after DM modeling. DM, diabetes ve veight and blood glucose levels in the table refer to diabetic rats only

\begin{tabular}{|c|c|c|c|c|c|c|}
\hline \multirow[b]{2}{*}{ Group } & \multirow[b]{2}{*}{$\begin{array}{c}\text { Incidence of } \\
\text { DM }\end{array}$} & \multirow[b]{2}{*}{ Weight (g) } & \multicolumn{2}{|c|}{ Day 4 after modeling } & \multicolumn{2}{|c|}{ Day 10 after modeling } \\
\hline & & & Weight (g) & $\begin{array}{l}\text { Blood glucose } \\
\text { (mmol/L) }\end{array}$ & Weight (g) & $\begin{array}{l}\text { Blood glucose } \\
(\mathrm{mmol} / \mathrm{L})\end{array}$ \\
\hline Normal & $0 / 20$ & $\begin{array}{l}286.4 \pm \\
19.2\end{array}$ & $\begin{array}{c}301.2 \pm \\
19.1\end{array}$ & $3.85 \pm 0.78$ & $\begin{array}{l}389.1 \pm \\
20.1 \#\end{array}$ & $6.68 \pm 0.88 \#$ \\
\hline $\begin{array}{l}35 \mathrm{mg} / \mathrm{kg} \\
\text { DM }\end{array}$ & $5 / 20$ & $\begin{array}{c}289.7 \pm \\
18.8\end{array}$ & $\begin{array}{c}289.1 \pm \\
18.9\end{array}$ & $20.65 \pm 3.01 *$ & $\begin{array}{c}224.7 \pm \\
16.6 * \#\end{array}$ & $23.81 \pm 3.65^{*} \#$ \\
\hline $\begin{array}{l}40 \mathrm{mg} / \mathrm{kg} \\
\mathrm{DM}\end{array}$ & $25 / 25$ & $\begin{array}{c}287.8 \pm \\
18.5\end{array}$ & $\begin{array}{c}287.2 \pm \\
20.3\end{array}$ & $21.65 \pm 3.99 *$ & $\begin{array}{l}230.6 \pm \\
17.7 * \#\end{array}$ & $25.22 \pm 3.11 * \#$ \\
\hline $\begin{array}{l}60 \mathrm{mg} / \mathrm{kg} \\
\mathrm{DM}\end{array}$ & $19(6$ dead $)$ & $\begin{array}{l}291.1 \pm \\
19.6\end{array}$ & $\begin{array}{c}288.6 \pm \\
19.3\end{array}$ & $23.21 \pm 3.88^{*}$ & $\begin{array}{c}226.1 \pm \\
18.8^{*} \# \\
\end{array}$ & $25.84 \pm 3.77^{*} \#$ \\
\hline
\end{tabular}


protein showed insignificant difference between two groups $(P$ $>0.05$ ) (Fig. 2B and 2C).

\section{miR-141 specifically binds to Rho-3'-UTR and down- regulates the expression of Rho gene at the post transcriptional level \\ Online analysis software} showed that there was a specific binding region between Rho3'UTR and miR-141 sequences, and Rho was the target gene of miR-141 (Fig. 3A). The luciferase reporter gene assay was performed to verify whether Rho was the target of miR-141 (Fig. 3B). The luciferase activity of Rho WT 3'UTR was significantly suppressed in the miR-141mimics group $(P<0.05)$, while the MUT 3'UTR luciferase activity was not inhibited. These results suggest that miR-141 may specifically bind to Rho3'-UTR and down-regulate the expression of Rho gene at the post transcriptional level.

in other grou signmicantly decreased as or a with the normal \& up, a we mRNA exprese of and ROCK2 $y$ 're slo antly increased (all $P$ ङ). I RNA expression of protel ss in the RhoA/ROCK cigna. thway and miR-141 ression showed in significant iff ence in comparison with blank group and NC group (all $P>0.05$ ). Compared with the blank group and the NC group, the expression of miR-141 in the miR141 mimics group was significantly increased, the expression of miR-141 had no difference in the siRNA-Rho group $(P>0.05)$, and the expression of RhoA and ROCK2 mRNA were significantly reduced

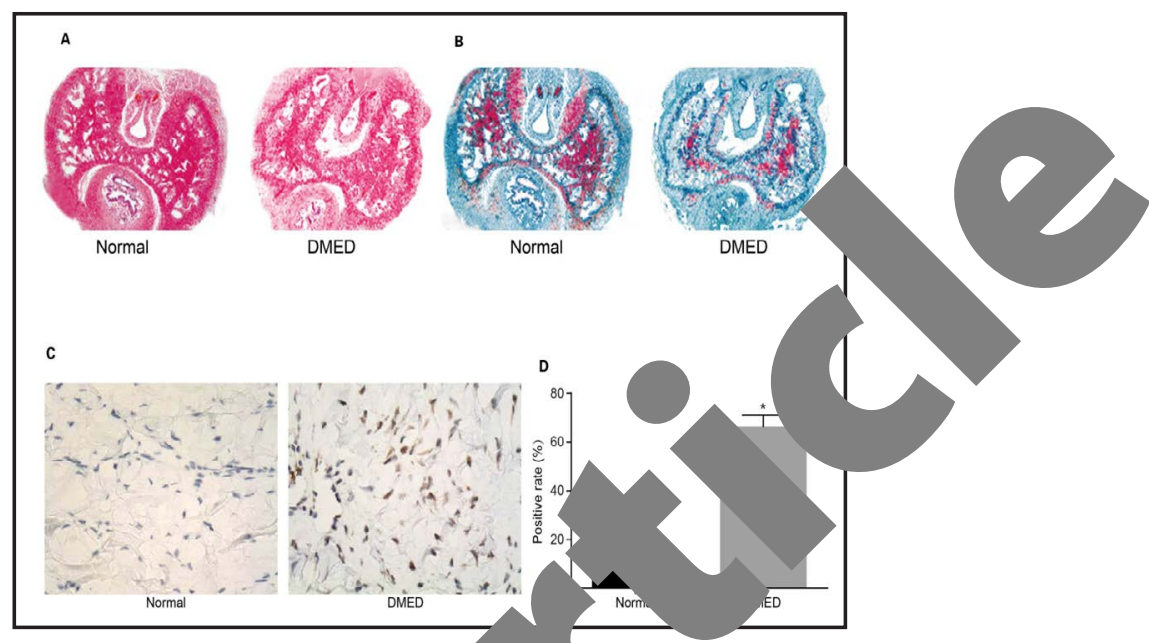

Fig. 1. The penile cavernous smo uscle cells of rats between normal and $D$ sups by sson staining (X 200). A: HE staining fo and D 2 D rats; B: Masson staining for normal rats the RhoA protein in the $\mathrm{F}$ corpus cavernosum tissues in the norm DMED grou nmunohistochemical staining of Rho pro statistica alysis of the positive rate of RhoA prote vion. ${ }^{*} \mathrm{P}<0.05$ compared with the rats in

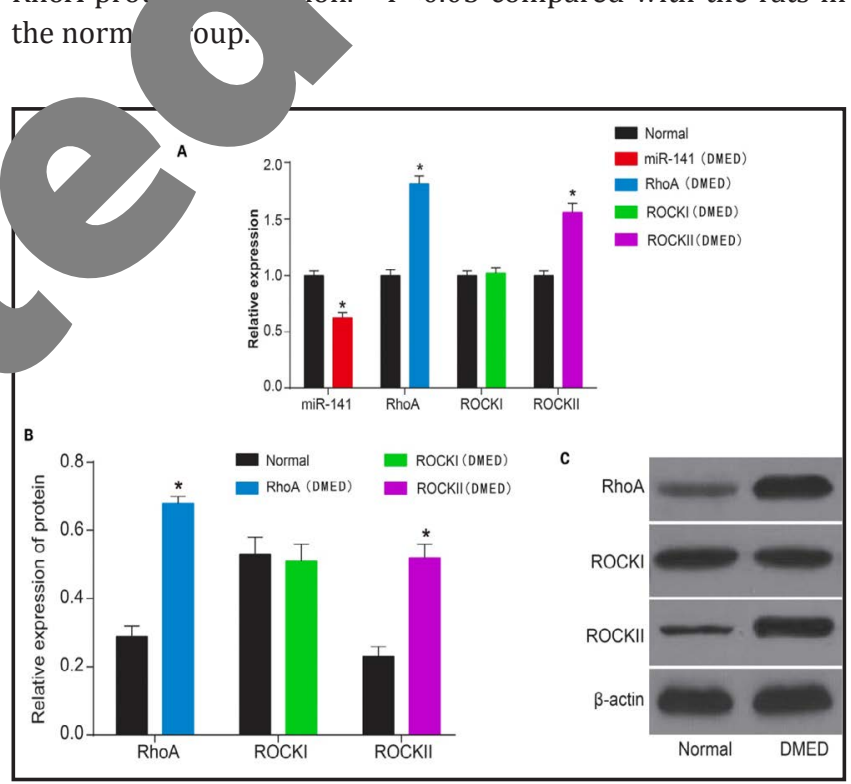

Fig. 2. Expressions of miR-141 and mRNA expressions of related proteins in the RhoA/ROCK signaling pathway in the penile corpus cavernosum tissues of rats. A: protein expressions of RhoA, ROCK1 and ROCK2 in the penile corpus cavernosum tissues of rats; B: statistical analysis chart for protein expressions of RhoA, ROCK1 and ROCK2 in the penile corpus cavernosum tissues of rats; C: western blotting for protein expressions of RhoA, ROCK1 and ROCK2 in the penile corpus cavernosum tissues of rats. ${ }^{*} \mathrm{P}<0.05$ compared with the normal group. 
Fig. 3. Relationship between Rho gene and miR-141. Online analysis software showed that there was a specific binding region between Rho3'UTR and miR-141 sequences, and Rho was the target gene of miR141 (A). The luciferase reporter gene assay was performed to verify whether Rho was the target of miR-141. The luciferase activity of Rho WT 3'UTR was significantly suppressed in the miR-141mimics

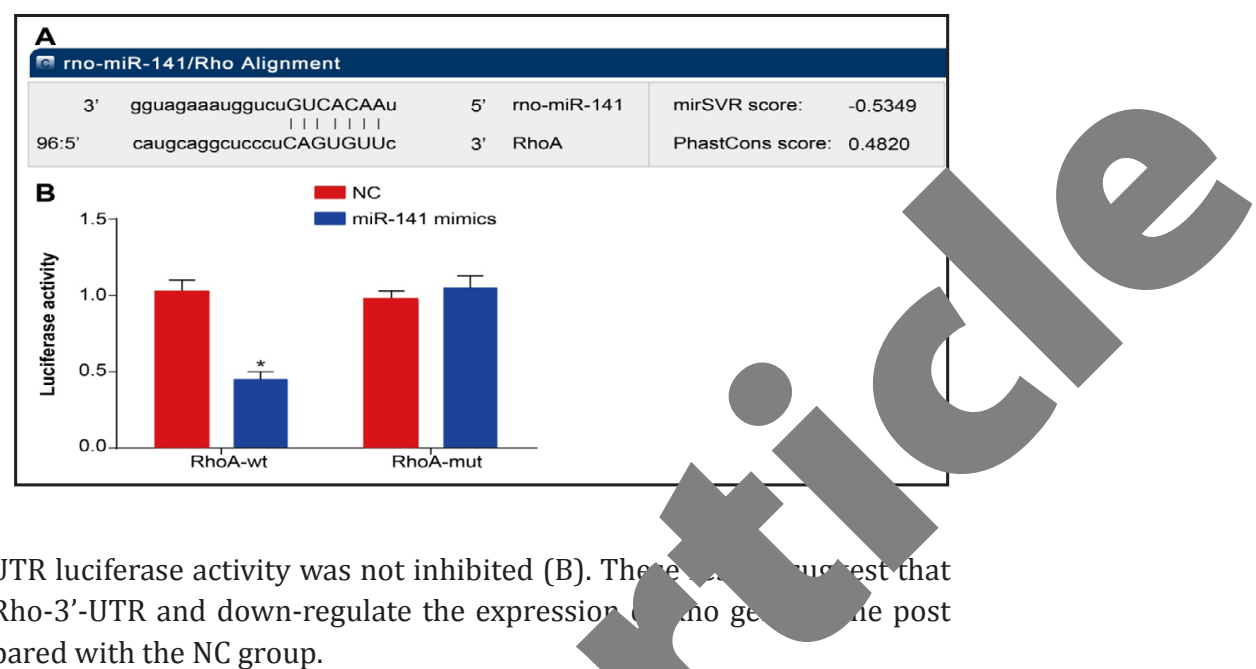
group as compared to the NC group, $(\mathrm{P}<0.05)$, while the MUT 3'UTR luciferase activity was not inhibited (B). The miR-141 may specifically bind to Rho-3'-UTR and down-regulate the expression transcriptional level. * $\mathrm{P}<0.05$ compared with the $\mathrm{NC}$ group.

in the miR-141 mimics group and the siRNA-Rho group in the miR-141 inhibitors group was decreased, and the ROCK2 were significantly increased (all $P<0.05$ ), the expre. + siRNA-Rho group was significantly lowered $<0.05$ ), $\mathrm{m}$ RhoA and ROCK2 were unaltered (both $P>0.0$ mRNA expression of ROCK1 in cells of each grour.

Expressions of RhoA and ROCK 2 protein $u$

Compared with the normal group, the detected by Western blotting were m? expressions of the RhoA/ROCK signal between the blank group and the NC NC groups, the expressions the siRNA-Rho group were A a th related proteins were insignificantly different 5); $\mathrm{m}$. expression sions of RhoA and 141 in the inhibitor the mRNA expressions of ifference was detected in $>0.05$ ) (rig. $4 \mathrm{~A}$ ). was significantly increas ${ }^{f}$ miR-141 inhibitors + si significant difference $\mathrm{w}$ 0.05) (Fig. 4B and

\section{inch} in cultured cells 1s of RhoA and ROCK2 protein as $d$ in other groups (all $P<0.05$ ). The ( > > 0.05). Compared with the blank and the 2 protein in the miR-141 mimics group and ntlv decreased, while in the miR-141 inhibitors group he expressions of RhoA and ROCK2 protein in the A-Rho group showed insignificant changes (both $P>0.05$ ). No und the expression of ROCK1 protein among groups (all $P>$

\section{Proliferat} groups. ignii

th rmal group, cell proliferation was significantly decreased in other difference was detected in the blank group and the NC group $(P>$ 0 05). $\mathrm{C}$ red witn the blank and NC groups, the proliferation rate of cells in the miR-141 $\checkmark$ gro $\quad$ d siRNA-Rho group was significantly accelerated $(P<0.05)$, and the rate of the $m, 141$ inhibitors group was decreased $(P<0.05)$; no significant difference was dete he miR-141 inhibitors + siRNA-Rho group on proliferation rate $(P>0.05)($ Fig.

8.

Comparison of cell cycle and apoptosis in each group after transfection

The PI staining was used to determine the cell cycle. The cell proportion at the G0/G1 phase in the normal group, the blank group, the NC group, the miR-141 mimics group, the miR-141 inhibitors group, the siRNA-Rho group and the miR-141 inhibitors + siRNA-Rho group was $76.23 \% \pm 2.06 \%, 50.26 \% \pm 3.13 \%, 51.32 \% \pm 2.36 \%, 38.26 \% \pm 2.31 \%, 65.35 \% \pm$ $2.16 \%, 41.39 \% \pm 2.42 \%$, and $51.25 \% \pm 2.52 \%$, respectively. The cells proportion at the $\mathrm{S}$ phase was $18.36 \% \pm 3.23 \%, 37.63 \% \pm 2.28 \%, 35.26 \% \pm 2.39 \%, 49.36 \% \pm 3.28 \%, 25.03 \% \pm 3.13 \%$, $48.34 \% \pm 2.76 \%$, and $36.23 \% \pm 2.18 \%$, respectively. Compared with the normal group, the proportion of cells at the G0/G1 phase was decreased and cells at the S phase were increased in other groups (all $P<0.05)$. Compared with the NC and the blank groups, the proportion

\section{KARGER}


of cells at the G0/G1 phase was decreased and cells at the $S$ phase were increased in the miR-141 mimics group and the siRNARho group (both $P<0.05$ ); the proportion of cells at the G0/G1 phase was increased and cells at the $S$ phase were decreased in the miR-141 inhibitors group $(P<$ 0.05 ); changes of cell cycles in the miR-141 inhibitors + siRNA-Rho group showed no difference $(P>$ 0.05) (Fig. 5).

The Annexin V-FITC/PI double staining was used to measure the apoptosis of cells. The apoptosis rates in the normal group, the blank group, the NC group, the miR-141 mimics group, the miR-141 inhibitors group, the siRNA-Rho group and miR-141 inhibitors + siRNA-Rho group were $5.55 \% \pm 1.95 \%, 37.64 \% \pm$ $3.25 \%, 38.35 \% \pm 2.89 \%, 27.33 \%$ $\pm 3.26 \%, 49.12 \% \pm 2.63 \%, 26.14 \%$ $\pm 1.49 \%$, and $40.82 \% \pm 2.38 \%$, respectively. Compared with the normal group, the apoptosis rate in the other groups was mar increased (all $P<0.05$ ) apoptosis rate was con rab. between the blank grou nd the NC group $(P>0.05)$. with the NC and th groups, the ape tes in the miR-141 min so or nd the signific whil e increased is tha $\mathrm{m}$ inhibitors group $(P$ f; the tosis rate in miRibitor + siRNA-Rho group how gnificant difference $(P$ 05) (rig. 6).

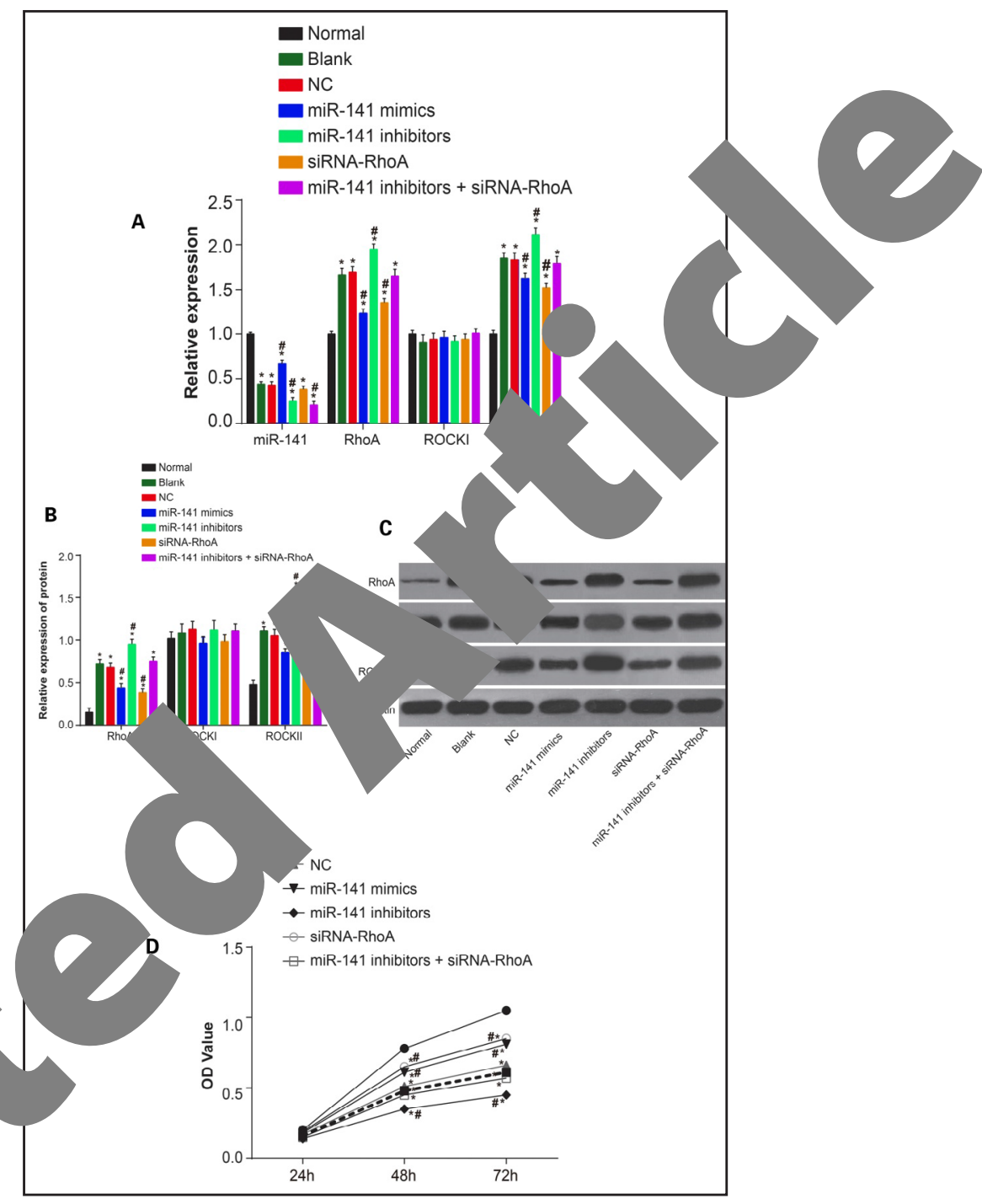

Fig. 4. miR-141 and mRNA of related proteins in the RhoA/ ROCK signaling pathway. A: expressions of miR-141 and mRNA of related proteins; B: protein expressions RhoA, ROCK1 and ROCK2 in cells after transfection, statistical analysis chart for protein expressions of RhoA, ROCK1 and ROCK2 of cells; C: Western blotting for protein expressions of RhoA, ROCK1 and ROCK2 of cells; D: changes of cell proliferation after cell transfection. * $\mathrm{P}<0.05$ compared with the normal group; \# $\mathrm{P}<0.05$ compared with the blank and the NC groups.

\section{Discussion}

Occurrence of DMED largely involves neural, vascular and smooth muscle lesions [16]. Type 1 and type 2 DM are related to the alterations in the level of several miRs in insulinsecreting cells as well as in insulin-target tissues [17]. However, miR141 correlation with DM or DMED is still unknown. Decreased miR141 expression has been correlated to other pathologies such as renal cell carcinoma cancer [18]. miR-141 expression was also obviously decreased in pancreatic cancer tissues [19].

RhoA and ROCK2 have been implicated in plentiful axonal guidance events in the development, such as involvement in the ephrin signaling, the repulsive guidance molecule

\section{KARGER}




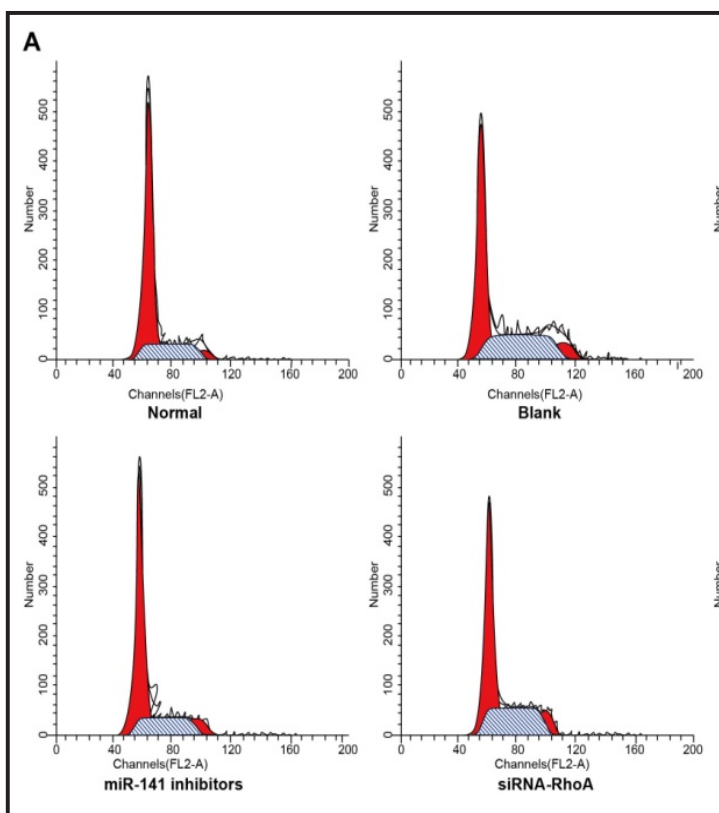

Fig. 5. Cell cycle in each group after cell transfection. The cell proportions at the G0/G1 phase and the S phas the miR-141 mimics group, the miR-141 inhibitors groun + siRNA-Rho group were presented. Compared with t' phase was decreased and cells at the S phase were in the NC and the blank groups, the proportion of alls a phase were increased in the miR-141 mimic of cells at the G0/G1 phase was increased a group $(\mathrm{P}<0.05)$; changes of cell cy $0.05)$. A: cell cycle diagram; B: per compared with the blank and th has
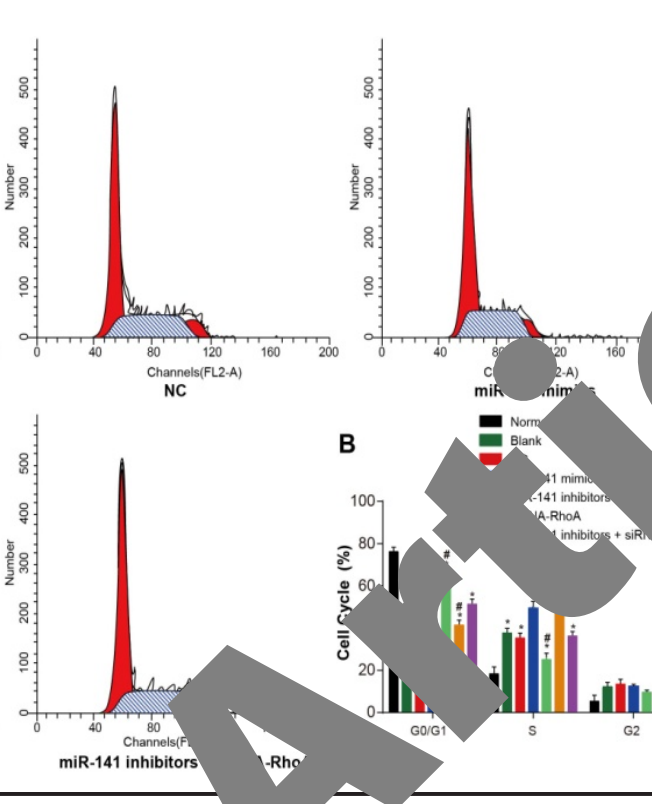

.

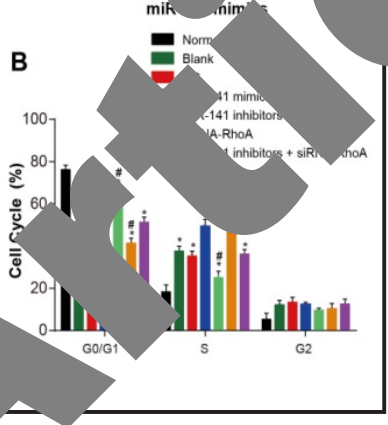

sed to determine the cell cycle. he blank group, the NC group, group and the miR-141 inhibitors up, the proportion of cells at the G0/G1 sed $\mathrm{i} \quad \mathrm{r}$ groups (all $\mathrm{P}<0.05)$. Compared with 1 phase was decreased and cells at the $\mathrm{S}$ thon
$S$ phase were decreased in the miR-141 inhibitors irs + siRNA-Rho group showed no difference $(\mathrm{P}>$ e of cer._. * $\mathrm{P}<0.05$ compared with the normal group; $\# \mathrm{P}<0.05$
(RGM) signaling, and th are involved in an abur. remodeling, diff ROCK and the w myosin phrsphat [? mouse por in the ciss caver regulate the RhoA/ROCK pathway in gastric smooth muscle [24]. our st , we first measured the expressions of miR-141 and the changes of the RhoA/ Ru ing pathways in the corpus cavernosum tissue of rats with diabetic ED and we nd cased expressions of miR-141 associated with up-regulation of RhoA and ROCK2. A A and ROCK2 genes were also highly expressed in rats with DMED. The role of RhoA/ Br pathway in the regulation of muscle contraction is well established in both visceral a vascular smooth muscle. Most current medical therapies for ED seek to maximize the endogenous signaling of NO. Certain etiologies like diabetes, however, are difficult to treat with current modalities. Thus new molecular targets are in urgent need [25]. Researchers have demonstrated the importance of the RhoA/ROCK signaling pathway in maintaining a flaccid state of the penile, and inhibition of the signaling potentiates smooth muscle relaxation in an NO-independent manner [26].

To further elucidate the link between miR-141 and the RhoA/ROCK signaling pathway, we identified Rho as the direct target genes of miR-141 by bioinformatics methods and then examined the mechanisms that lead to changes in miR-141 and RhoA/ROCK pathway. 

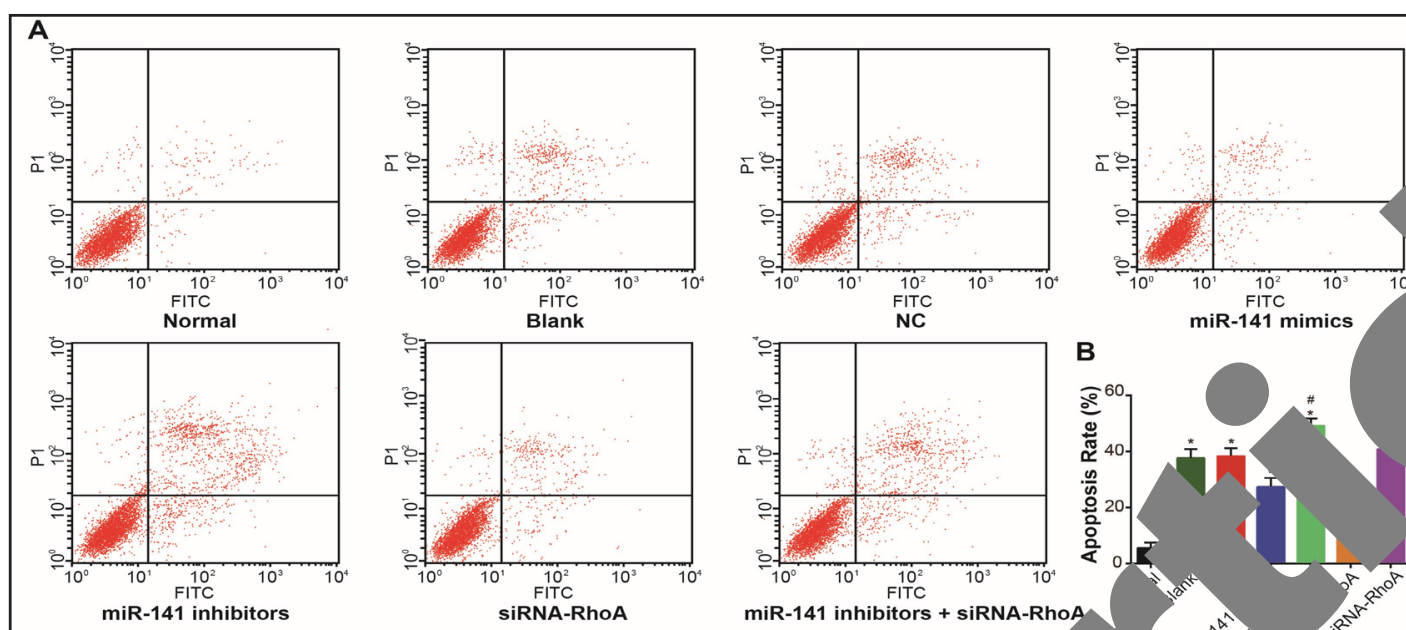

miR-141 mimics

miR-141 inhibitors

miR-141 inhibitors + siRNA-RhoA
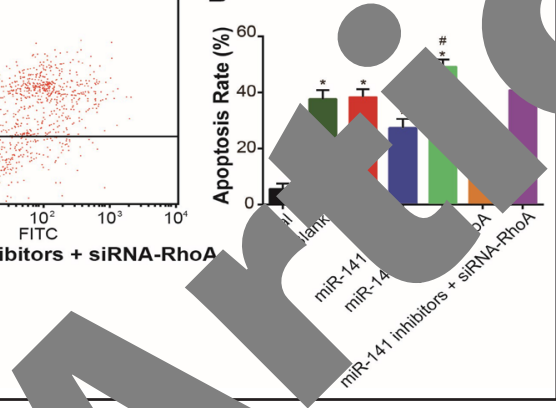

Fig. 6. Cell apoptosis rate after cell transfection. The Annexin V-FITC/ the apoptosis of cells. The apoptosis rates in the normal oroup, the bla mimics group, the miR-141 inhibitors group, the siR ho group an $\checkmark$ was used to measure ap, the NC group, the miR-141 group were presented. Compared with the normal grou poptosis $\mathrm{r}_{\mathrm{a}}$ in other groups was markedly increased (all $\mathrm{P}<0.05$ ). The apoptosis rate was comp? reen the blank group and NC group ( $\mathrm{P}>$ 0.05). Compared with the NC and the blank groups, popt tes in the miR-141 mimics group and the siRNA-Rho group were decreased significantly, $\mathrm{w}$ ror ireased in the miR-141 inhibitors group $(\mathrm{P}<0.05)$; the apoptosis rate in miR-141 inhil group showed insignificant difference $(\mathrm{P}>$ $0.05)$. A: cell apoptosis diagram; B: percenta of cotic cells. ${ }^{*} \mathrm{P}<0.05$ compared with the normal group; \# $\mathrm{P}<0.05$ compared with the blank` ${ }^{\wedge}$ nd the

We investigated the effects $C$ regulated expression of $\mathrm{r}$ cells associated with do of RhoA and ROCK2 Previously, we rem-ed. via down-regu' whereby play 3 ? effector of the tre? $\mathrm{t}$ of $\mathrm{D}$ ap

sbow d increased RhoA protein by immunostaining only, and RhoA and ROCK by est tting only. However, increased expression not necessarily indicates increased vity. In our parallel study, we found that ripasudil, a selective ROCK inhibitor, could a ve the erectile function in diabetic rats (unpublished data). Our findings, alongside those from a previous report [28], indicate that DMED can be alleviated by suppressing

In summary, decreased expression of miR-141 was associated with up-regulation of RhoA and ROCK2 in the RhoA/ROCK signaling pathway in DMED. miR-141 inhibits the growth of penile cavernous smooth muscle cells associated with down-regulation of the RhoA/Rho kinase signaling pathway in vitro. The RhoA/ROCK signaling pathway might be a promising target for the treatment of DMED. 


\section{Cellular Physiology Cell Physiol Biochem 2018;48:348-360 \begin{tabular}{l|l} 
and Biochemistry $10.1159 / 000491741$ \\
Published online: July 16, 2018 & $\begin{array}{l}\text { O } 2018 \text { The Author(s). Published by S. Karger AG, Basel } \\
\text { www.karger.com/cpb }\end{array}$ \\
\cline { 2 - 3 }
\end{tabular}}

Zhang et al.: MiRNA-141 and DMED

\section{Acknowledgements}

The study was supported by funding from Jilin University.

\section{Disclosure Statement}

No conflicts of interest exist.

\section{References}

1 Shaw JE, Sicree RA, Zimmet PZ: Global estimates of the prevalence of diabetes for 201 Res Clin Pract 2010;87:4-14.

-2 Stefek M: Natural flavonoids as potential multifunctional agents in prevention of di Interdiscip Toxicol 2011;4:69-77.

3 Braun M, Wassmer G, Klotz T, Reifenrath B, Mathers M, Engelmann idemiolog, actile dysfunction: results of the 'Cologne Male Survey'. Int J Impot Res 2000;12:305

4 Al-Kuraishy HM, Al-Gareeb AI: Erectile Dysfunction and Low Sex D Potential Role of Diabetic Pharmacotherapy. J Clin Diagn Res 2016;1

5 Minami H, Furukawa S, Sakai T, Niiya T, Miyaoka H, M re T, Yamamo K, Ueda T, Senba H, Torisu M, Tanigawa T, Matsuura b, Y, Miyake Y: sical activity and prevalence of erectile dysfunction in Japanese patients with type 2 d: vellitus: The Dogo Study. J Diabetes Investig 2018;9:193-198

6 Ogbera OA, Sonny C, Olufemi F, Wale A: Hypogonad type 2 diabetes mellitus. J Coll Physicians S

7 Pop-Busui R, Hotaling J, Braffett BH, Clea AV; DCCT/EDIC Research Group: Cardio urinary tract symptoms in me 2051. nd si mal total testosterone levels in men with / -521.

Okumura N, Fujii K, Kagam Mrak au omic neuropathy, erectile dysfunction and lower indings from the DCCT/EDIC. J Urol 2015;193:2045Kinase Signaling Pathwa nvolved Death of Corneal Endothelium. Invest Ophthalmol Vis Sci 2016;57:6843-6851.

-9 Uvin P, Albersen M-Bolle DJ, Van der A vardenafil o he corpus cavernosum tissue of patients with

10 Lup di L: Acute exacerbations of chronic obstructive pulmonary disease: are antibiotics need $\quad$ Jespir Crit Care Med 2010;181:102-103.

A Y, L. Song Z, Xu KK, Wu SB, Li ZJ: Expression and regulation of microRNA-29a and microRNA-29c arly dia _, tic rat cataract formation. Int J Ophthalmol 2016;9:1719-1724.

g L, Luo LH, Duan ZF, Li XL, Yin CH, Sun X: The Effect of microRNA-328 antagomir on erectile dysiunction in streptozotocin-induced diabetic rats. Biomed Pharmacother 2017;92:888-895. hang L, Deng T, Li X, Liu H, Zhou H, Ma J, Wu M, Zhou M, Shen S, Li X, Niu Z, Zhang W, Shi L, Xiang B, Lu , Wang L, Li D, Tang H, Li G: microRNA-141 is involved in a nasopharyngeal carcinoma-related genes network. Carcinogenesis 2010;31:559-566.

14 Saito S, Thuc LC, Teshima Y, Nakada C, Nishio S, Kondo H, Fukui A, Abe I, Ebata Y, Saikawa T, Moriyama M, Takahashi N: Glucose Fluctuations Aggravate Cardiac Susceptibility to Ischemia/Reperfusion Injury by Modulating MicroRNAs Expression. Circ J 2016;80:186-195.

15 Pan F, Xu J, Zhang Q, Qiu X, Yu W, Xia J, Chen T, Pan L, Chen Y, Dai Y: Identification and characterization of the MicroRNA profile in aging rats with erectile dysfunction. J Sex Med 2014;11:1646-1656.

16 He Y, He W, Qin G, Luo J, Xiao M: Transplantation KCNMA1 modified bone marrow-mesenchymal stem cell therapy for diabetes mellitus-induced erectile dysfunction. Andrologia 2014;46:479-486. 


\section{Cellular Physiology Cell Physiol Biochem 2018;48:348-360

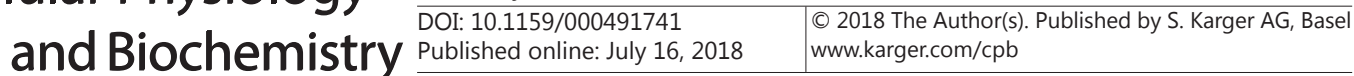

Zhang et al.: MiRNA-141 and DMED

17 Guay C, Roggli E, Nesca V, Jacovetti C, Regazzi R: Diabetes mellitus, a microRNA-related disease? Transl Res 2011;157:253-264.

18 Chen X, Wang X, Ruan A, Han W, Zhao Y, Lu X, Xiao P, Shi H, Wang R, Chen L, Chen S, Du Q, Yang H, Zhang $\mathrm{X}$ : miR-141 is a key regulator of renal cell carcinoma proliferation and metastasis by controlling EphA2 expression. Clin Cancer Res 2014;20:2617-2630.

19 Zhao G, Wang B, Liu Y, Zhang JG, Deng SC, Qin Q, Tian K, Li X, Zhu S, Niu Y, Gong Q Wang CY: miRNA-141, downregulated in pancreatic cancer, inhibits cell proliferation and invasion by directly targeting MAP4K4. Mol Cancer Ther 2013;12:2569-2580.

-20 Duffy P, Schmandke A, Schmandke A, Sigworth J, Narumiya S, Cafferty WB, Strittmatter SM: Pho-assoc kinase II (ROCKII) limits axonal growth after trauma within the adult mouse spinal cord. J 2009;29:15266-15276.

-21 Wu XD, Liu WL, Zeng K, Lei HY, Zhang QG, Zhou SQ, Xu SY: Advanced glycation end pro to tiva. miRNA/RhoA/ROCK2 pathway in endothelial cells. Microcirculation 2014;21:178-18

22 Hong J, Li D, Cao W: Rho Kinase ROCK2 Mediates Acid-Induced NADPH Oxidase NOY Human Esophageal Adenocarcinoma Cells. PLoS One 2016;11:e0149735.

-23 Priviero FB, Jin LM, Ying Z, Teixeira CE, Webb RC: Up-regulation of the RhoA/R in corpus cavernosum from endothelial nitric-oxide synthase (NOS not neuro se signaling pathway Pharmacol Exp Ther 2010;333:184-192.

24 Mahavadi S, Sriwai W, Manion O, Grider JR, Murthy KS: Diabetes-in upregulation of RhoA/Rho kinase pathway and hypercontractility o1 2017;12:e0178574.

-25 Sopko NA, Hannan JL, Bivalacqua TJ: Understanding and targeting the Rho kinase pathway is dysfunction. Nat Rev Urol 2014;11:622628.

26 Thoma C: Erectile dysfunction: Too much ROCK - e

27 Zhang Y, Jia L, Zhang Y, Ji W, Li H: Angiotensim-ilen n blo at Rev Urol 2017;14:6. ates Erectile Dysfunction Through DownRegulating the Rhoa/Rho Kinase Signalir at. in Rass with Diabetes Mellitus. Cell Physiol Biochem 2018;45:419-427.

28 Sezen SF, Lagoda G, Musicki B improves erectile function in $\mathrm{d}$ rats: a run neuronal ROCK. J Sex Med 2014;11:2164-2171.

\section{4.} S, null mice. J

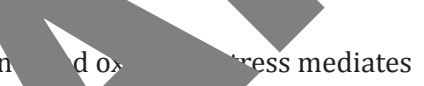
mou muscle. PLoS One 